\title{
Evolution of Eusociality: The Advantage of Assured Fitness Returns
}

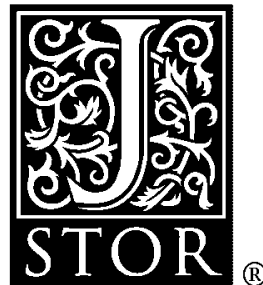

\author{
Raghavendra Gadagkar
}

Philosophical Transactions: Biological Sciences, Vol. 329, No. 1252. (Jul. 30, 1990), pp. 17-25.

Stable URL:

http://links.jstor.org/sici?sici=0962-8436\%2819900730\%29329\%3A1252\%3C17\%3AEOETAO\%3E2.0.CO\%3B2-X

Philosophical Transactions: Biological Sciences is currently published by The Royal Society.

Your use of the JSTOR archive indicates your acceptance of JSTOR's Terms and Conditions of Use, available at http://www.jstor.org/about/terms.html. JSTOR's Terms and Conditions of Use provides, in part, that unless you have obtained prior permission, you may not download an entire issue of a journal or multiple copies of articles, and you may use content in the JSTOR archive only for your personal, non-commercial use.

Please contact the publisher regarding any further use of this work. Publisher contact information may be obtained at http://www.jstor.org/journals/rsl.html.

Each copy of any part of a JSTOR transmission must contain the same copyright notice that appears on the screen or printed page of such transmission.

JSTOR is an independent not-for-profit organization dedicated to creating and preserving a digital archive of scholarly journals. For more information regarding JSTOR, please contact support@ jstor.org. 


\title{
Evolution of eusociality: the advantage of assured fitness returns
}

\author{
RAGHAVENDRA GADAGKAR \\ Centre for Ecological Sciences and Centre for Theoretical Studies, Indian Institute of Science, Bangalore 560012, India
}

\begin{abstract}
SUMMARY
Delineation of the selective pressures responsible for the evolution of sterile worker castes found in social insect colonies remains a major unsolved problem in evolutionary biology. There has therefore been a great deal of interest in suggesting ways by which the inclusive fitness of sterile workers can potentially be larger than those of solitary nest-builders. Queller's (1989) head-start hypothesis (Proc. natn. Acad. Sci. U.S.A. 86, 3224) suggests that workers may gain relatively more inclusive fitness because they have access to young of various ages which can be quickly brought to the age of independence, whereas a solitary foundress has to survive for the entire duration of the development of her brood. I argue here that Queller's quantitative analysis is incorrect because it gives an unfair advantage to workers, either by giving full credit of rearing an offspring to a worker who only cared for it for a short while or, by assuming that a worker can do much more work per unit time than a solitary foundress. I show, however, that workers do indeed have an advantage over solitary foundresses because they have assured fitness returns, even if in small amounts, for short periods of work. This results from a different reckoning from that used by Queller and gives a more moderate advantage, arising essentially from saving the wasted effort that occurs when lone foundress nests fail. Using field and laboratory data on the primitively eusocial wasp Ropalidia marginata, and re-analysing data on the four species of polistine wasps used by Queller, I show that such an 'assured fitness returns' model provides a selective pressure for the evolution of worker behaviour which is at least about as strong as that of haplodiploidy, but free from such requirements of the latter as high levels of worker-brood genetic relatedness and ability of workers to manipulate brood sex ratios.
\end{abstract}

\section{INTRODUGTION}

Many insects that live in social groups are characterized by overlap of generations, co-operative brood care and a reproductive caste differentiation into fertile reproductive castes and sterile worker castes. Such eusociality (Michener 1969; Wilson 1971) is exemplified by almost all ants (some appear to have lost the trait secondarily), some bees and wasps, all termites and also a single mammalian species, the naked mole rat (see Jarvis 1981). How natural selection can favour sterile worker castes over solitary reproducers has long been a paradox in evolutionary biology (Darwin 1859, pp. 268-273). Hamilton's (1964a,b) inclusive fitness theory or, the theory of kin selection as it is often called, helps formalize the paradox and suggests some possible solutions. A useful way of stating Hamilton's theory is that an altruistic (worker) allele will be selected if

$\Delta w^{*} r^{*}>\Delta w r$

where $\Delta w$ is the number of offspring that a solitary female rears on her own and $r$ is her genetic relatedness to them $(=0.5)$, whereas $\Delta w^{*}$ is the number of young that are reared in a colony because of a worker's help and $r^{*}$ is the genetic relatedness between workers and the brood they rear (Craig 1979; Queller 1989).

Inequality (1) can be achieved if $\Delta w^{*}$ is greater than
$\Delta w$, i.e. an individual is capable of rearing more relatives in a colony than it can rear offspring on its own. When this happens in any species, it may be said to be ecologically or physiologically pre-disposed to the evolution of eusociality. Inequality (1) may also be achieved by $r^{*}$ being greater than $r$, i.e. the average genetic relatedness to relatives is greater than that to offspring. When this happens in a species, it may be said to be genetically pre-disposed to the evolution of eusociality (Gadagkar 1985a). Although the malehaploid genetic system of the Hymenoptera, to which most of the eusocial species belong, can cause such genetic pre-disposition (Hamilton 1964a,b, 1972), polyandry (multiple mating by the queen) and polygyny (the presence of more than one egg-layer in a colony) often lower genetic relatedness between workers and the brood they rear. Any genetic predisposition towards eusociality caused by haplodiploidy is therefore likely to be obliterated (WestEberhard 1978; Page \& Metcalf 1982; Starr 1984; Gadagkar 1985 b, 1990b; Muralidharan et al. 1986; Page 1986; Ross 1986; Venkataraman et al. 1988; Strassmann et al. 1988). Inequalities between $\Delta w^{*}$ and $\Delta w$, i.e. the productivities, are perhaps more easily achieved either because of the greater risks of predation and parasitism in the solitary mode (Lin \& Michener 1972; Gibo 1978; Queller et al. 1988; Gadagkar 
$1990 a$ ), other advantages of group life (Gamboa 1978) or because of differential fertilities of the individuals opting for reproductive and worker roles (Alexander 1974; West-Eberhard 1975; Gadagkar et al. 1988, 1990).

\section{THE HEAD-START HYPOTHESIS}

Queller (1989) has rewritten inequality (1) as $r^{*} s^{*} b^{*}>r s b$

where ' $s$ is the probability of survival of a solitary female up until the time when she rears her first offspring to independence. Given that she survives this long, $b$ is the number of adult offspring that results from her efforts.' On the left-hand side, ' $s *$ and $b^{*}$ are the corresponding parameters for a worker, with the latter being what a worker's efforts add to the colony's production of reproductives'. Queller (1989) has argued that inequality (2) will be achieved rather easily because $s^{*}$ will be relatively high compared with $s$. The reason Queller assigns to this difference between $s^{*}$ and $s$ is that a worker has a 'reproductive head start' because, 'there are already young of various ages present on her natal nest' so that 'Her efforts can immediately result in some of these reaching the age of independence, so $s^{*}=1$ '. On the other hand, 'a solitary female must survive through the entire egg-toadult developmental period of her offspring to have any reproductive success at all'. Notice that he sets $s^{*}=1$ rather than just the biologically more realistic inequality, $s^{*}>s$.

For lack of sufficient data on solitary foundresses, Queller (1989) has used survivorship data on workers to estimate $s$ or the probability of survival of solitary foundresses for the duration of their species-specific brood developmental periods to be $0.057,0.187,0.097$ and 0.167 , respectively for four polistine wasps, namely: Polistes exclamans, $P$. chinensis, $P$. gallicus and Mischocyttarus drewseni. Assuming $s^{*}=1$ (his reasons for doing so are outlined above) and $b=b^{*}$ (in an attempt to assume equal productivities of solitary foundresses and workers), he computes threshold $r^{*}$ values required to maintain eusociality in these species to be equal to $0.03,0.09,0.05$ and 0.08 , respectively. Presenting the same results in another perhaps more spectacular way, Queller (1989) argues that if $r^{*}$ is equal to $r$, the threshold values of $b / b^{*}$ for the evolution of eusociality attain impressive values of $17.4,5.3,10.3$ and 6.0, respectively for those four species.

Queller (1989) has interpreted these results to mean that workers would break even (have the same fitness) with their solitary counterparts in spite of rearing relatives with an average level of genetic relatedness to themselves being as low as 0.03 to 0.09 , although solitary foundresses rear offspring who are related to them by 0.5 . If workers were also related to the relatives they rear by $0.5\left(r^{*}=r=0.5\right)$, then they would break even, despite their solitary counterparts being capable of rearing 5.3-17.4 times the number of young ones that they themselves can. Queller compares this 'strength' of his head start hypothesis with a maximum 'strength' of 1.5 that may be assigned to the haplodiploidy hypothesis. With a relatedness of 0.75 to their brood (if the brood consists only of full-sisters), workers will break even under the haplodiploidy hypothesis if their solitary counterparts reared 1.5 times the brood that they themselves did. This makes the head-start hypothesis appear 3-12 times 'stronger' than the haplodiploidy hypothesis for the species being considered by Queller (1989). Such a powerful force favouring sociality as Queller's head-start hypothesis has seldom been suggested.

\section{A FLAW IN THE HEAD-START HYPOTHESIS}

In inequality (2), Queller's (1989) definition of $b^{*}$ is open to at least two interpretations. First, $b^{*}$ may be thought of as being analogous to $b$ in that it is the number of offspring contributed by a worker, provided she survives for the entire brood developmental period. With this interpretation of $b^{*}$, there would clearly be a flaw in the head-start hypothesis. This pertains to the assumption that $s^{*}=1$ because 'there are already young of various ages present' on the natal nest of a worker. This assumption amounts to giving full credit of rearing one offspring from egg to adulthood (independence) to a worker who only eclosed one or a few days before the completion of development of the offspring and thus fed it, or perhaps guarded it against parasites, only during that one or those few days. Such a procedure overlooks the fact that the queen or other workers performed all the duties of rearing this offspring from egg to the present stage at which the worker in question found it. In as much as the credit (contribution to fitness) for this part of the work should go to the queen or other workers as the case may be, it should not go to this female. The contribution to any worker's fitness should clearly be in proportion to her contribution towards the rearing of each offspring; otherwise full fitness for rearing a larva gets assigned to several workers on account of the same larva.

A second possible interpretation (pointed out to me by reviewers of previous versions of this paper) of $b^{*}$ in inequality (2) is that it is the number of adult offspring that result from a worker's efforts given that she survives long enough to produce adults (any adults at all). This interpretation may perhaps be made from the following definition of the condition $b=b^{*}$ : 'Assume for the moment that workers and solitary females are equally productive, given that they have survived to begin producing adults $\left(b=b^{*}\right)$.' (Queller 1989). With this interpretation, $b$ is the number of offspring a solitary foundress rears, provided she survives for the entire brood developmental period but, $b^{*}$ is quite different in that, it is only the number of individuals reared by a worker provided she survives from the time of her joining the nest and the eclosion of the first adult individual on the nest. Now the assumption that $b=b^{*}$ seems unrealistic and certainly does not mean that solitary females and workers are 'equally productive'; $b$ and $b^{*}$ are the number of individuals reared by surviving for very different periods of time. With this definition, setting $b=b^{*}$ is equivalent to assuming that workers are capable of doing more work per unit time than solitary found- 
resses. It is therefore no longer meaningful to compute a threshold $r^{*}$ and interpret it as the threshold relatedness required between workers and brood for workers to break even with solitary foundresses. Similarly, the ratio $b / b^{*}$ can no longer be interpreted to mean that workers would break even in spite of solitary foundresses being capable of rearing that many $\left(b / b^{*}\right)$ more offspring than they themselves can. Thus, with either interpretation of $b^{*}$, Queller's (1989) headstart hypothesis gives an unfair advantage to workers, in one case by making $s^{*}=1$ unreasonable and in the other case by making $b=b^{*}$ unreasonable. On the other hand, Queller (1989) gives no such unfair advantage either to workers or to solitary foundresses when estimating the 'strength' of the haplodiploidy hypothesis as 1.5 . To arrive at a threshold $b / b^{*}$ value of 1.5 for the haplodiploidy hypothesis, it is not necessary to define $b$ and $b^{*}$ differently. Both can be defined as the number of individuals reared by solitary foundresses or workers (as the case may be), provided they survive for the entire brood developmental period. I argue therefore that the apparent strength of Queller's (1989) head-start hypothesis is partly due to the unfair advantage that he gives to workers in formulating his model.

\section{THE ADVANTAGE OF ASSURED FITNESS RETURNS}

There is, however, an advantage that a worker has over a solitary foundress which may be described as an advantage of assured fitness returns. A worker may care for some larvae during their very early lives and may die long before they reach the age of independence. Nevertheless, she will derive some measure of fitness for her efforts because some other worker is likely to care for the same larvae and bring them to the age of independence. In contrast, a solitary foundress loses all if she dies even a few days before her first offspring reach the age of independence. Being alone, she has no assured fitness returns.

Thus a relative advantage over solitary foundresses accrues to a worker in a colony not only when she has access to some larvae close to the age of independence, but also when she works for very young larvae and dies before they reach the age of independence. This latter scenario is not implied by the phrase 'head start'. For this reason I suggest the phrase 'assured fitness returns' which implies that workers are assured some fitness returns for their labour even if they work only for a fraction of the brood developmental period, and, irrespective of whether they do so in the beginning or later part of the brood developmental period. But the more serious problem with Queller's (1989) head-start hypothesis is his simultaneously setting $s^{*}=1$ and $b=b^{*}$. In quantifying the advantage of assured fitness returns therefore, I do not set $s^{*}=1$ and outline below a procedure for giving credit to a worker only for the fraction of her contribution to brood development.

For simplicity, I imagine a species in which each nest produces only one synchronous batch of brood. In other words, all eggs are laid on a given day which eclose as adults a certain number of days later after which the nest is abandoned. I also rewrite inequality (2) as:

$$
r^{*} \sigma^{*} \beta^{*}>r s b \text {. }
$$

On the right-hand side, $r$ is the coefficient of genetic relatedness between a solitary foundress and her brood, $s$ is the probability of her surviving for the entire developmental period of her brood and $b$ is the number of offspring reared by her provided she survives for the entire brood developmental period, all identical to the right-hand side of inequality (2). On the left-hand side, I have a new term, $\beta^{*}$, which is analogous to Queller's (1989) $b^{*}$ (in the left-hand side of inequality 2 ). But because $b^{*}$ in inequality (2) is open to more than one interpretation, I call this $\beta^{*}$ and define it as the number of individuals that result from the efforts of a worker provided she survives for the entire brood developmental period. Here the assumption that $b=\beta^{*}$ would clearly mean that both solitary foundresses and workers are capable of doing the same amount of work per unit time; if they survive for the same period of time, they rear the same number of individuals.

In computing the fitness of a solitary foundress (in the right-hand side of inequality (3)), $b$ is multiplied by $s$ to account for the fact that not all solitary foundresses would be expected to survive for the entire brood developmental period. This procedure is equivalent to assigning a value of zero to all solitary foundresses who die before the end of the brood developmental period, and a value of $b$ to all those who survive to the end of the brood developmental period. Notice that no additional value is assigned for surviving beyond the brood developmental period because I am only considering one synchronously produced batch of brood.

In computing the fitness of a worker (in the left-hand side of inequality (3)), I must similarly discount $\beta^{*}$ because not all workers would be expected to survive for the entire brood developmental period. However, this cannot be done merely by multiplying $\beta^{*}$ by the probability of survival of a worker till the end of the brood developmental period. The essential point of assured fitness returns is that even those workers who die before the brood reach independence get some measure of fitness. In fact, I wish to assign fitness to workers in proportion to the fraction of their contribution to brood development, irrespective of whether they cared for the brood in the beginning, middle or later part of their development. In other words $\beta^{*}$ should be discounted by a factor which is equal to the fraction of the brood developmental period for which a worker survives. I graphically illustrate this difference between the procedures for computing the fitness of a solitary foundress and that of a worker with an example (figure 1). Let $b=\beta^{*}$ and the brood developmental period be equal to $n$ days. If a solitary foundress has a lifespan of $x$ days (where $x<n$ ), I give her credit for rearing zero offspring but if a worker has a lifespan of $x$ days then I give her credit for rearing $\left(\beta^{*} x\right) / n$ individuals. If a solitary foundress has a lifespan of $y$ days (where $y>n$ ), then I give her credit for rearing $b$ offspring. Similarly, if a worker has a lifespan of $y$ days then I give her credit for rearing $\beta^{*}$ 


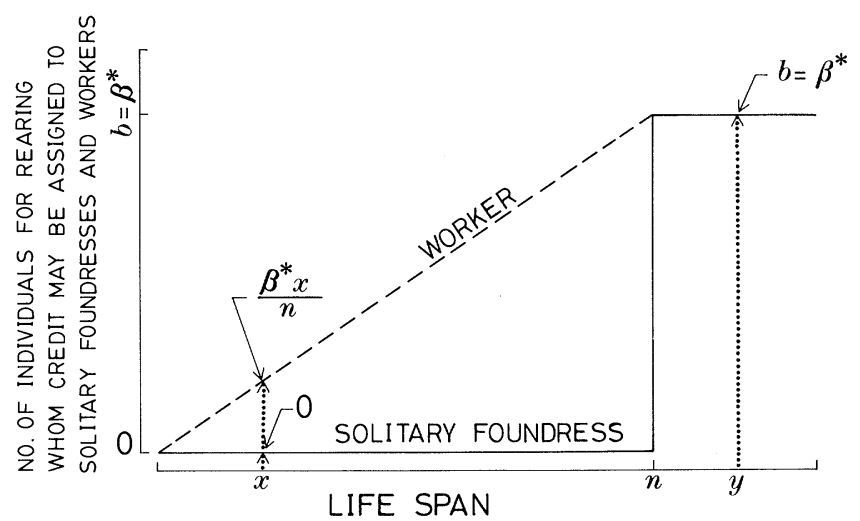

Figure 1. A procedure for assigning credit for rearing brood to solitary foundresses and workers with different lifespans. $b=\beta^{*}=$ the number of individuals that solitary foundresses and workers respectively, can rear provided they survive for the entire brood developmental period, and $n=$ brood developmental period in days. Solitary foundresses get zero credit if they survive for less than $n$ days and $b$ if they survive for $n$ or more days. Workers, on the other hand, get credit in proportion to the fraction of brood developmental period that they survive with a maximum of $\beta^{*}$ if they survive for $n$ or more days. Thus a solitary foundress who survives for $x$ days (where $x<n$ ) gets zero credit but a worker who survives for $x$ days gets a credit of $\left(\beta^{*} x\right) / n$. A solitary foundress who survives for $y$ days (where $y>n$ ) gets a credit of $b$ and a worker who survives for $y$ days gets a credit of $\beta^{*}$. Nobody gets more credit than $b$ or $\beta^{*}$ even if they survive for longer than $n$ days because we are considering only one synchronously produced batch of brood. This is the reason for the flat portion of the curves beyond $n$.

individuals. Nobody gets more credit than $b$ or $\beta^{*}$ in spite of surviving for longer than $n$ days because I am only considering one synchronously produced batch of brood.

To understand if worker behaviour will be selected, it is not enough to be able to compute the fitness of a solitary foundress or a worker whose lifespan is given (as in the example above). Instead, it is essential to be able to compute the expected fitness of average individuals taking up solitary foundress- or workerroles. In the case of solitary foundresses this is a simple matter. $r s b$ is itself the fitness expected for an average individual taking up the role of a solitary foundress because, $s$ is also the proportion of individuals who survive for the entire brood developmental period. $s b$ is therefore equivalent to a weighted average of the credit that accrues to solitary foundresses with different lifespans. In the case of workers this is not so simple. The factor by which $\beta^{*}$ needs to be discounted is not simply related to the proportion of workers who survive till the end of the brood developmental period. Because workers get fitness returns even if they work only for a fraction of the brood developmental period, this factor would be a function of the proportion of individuals who survive for each successive time period until the brood developmental period is completed. In other words, it would be a function of the shape of the survivorship curve. To distinguish this factor from Queller's (1989) $s^{*}$, I call it $\sigma^{*}$ (in the left-hand side of inequality 3 ) and compute it as follows:

$\sigma^{*}=\sum_{i=1}^{n-1} p_{i}(i / n)+\sum_{i=n}^{\infty} p_{i}$

where $p_{i}$ is the proportion of workers who have a lifespan of $i$ days (i.e. those that die on day $i+1$ ) and $n$ is the brood developmental period in days. When $\beta^{*}$ is multiplied by $\sigma^{*}$, the first term in equation (4) is equivalent to giving credit for rearing $\left(\beta^{*} i\right) / n$ individuals to those workers who survive for $i$ days (where $i<n$ ) and giving credit for rearing $\beta^{*}$ individuals to all workers who survive for $n$ or more days. Once again, workers who survive for more than $n$ days get credit for rearing no more than $\beta^{*}$ individuals because of the assumption of one synchronously produced batch of brood. Thus $\sigma^{*} \beta^{*}$ (in the left-hand side of inequality (3)) is equivalent to a weighted average of the credit that accrues to workers with different lifespans. The only other term in the left hand side of inequality (3) is $r^{*}$ which of course is the coefficient of genetic relatedness between workers and the brood they rear. Thus $r^{*} \sigma^{*} \beta^{*}$ is the fitness of an average individual adopting the role of a worker.

\section{THE PRIMITIVELY EUSOGIAL WASP ROPALIDIA MARGINATA}

I now apply the assured fitness returns model to data on the primitively eusocial wasp Ropalidia marginata (Lep.) (Hymenoptera: Vespidae) (Gadagkar 1980, 1985 a, 1990; Gadagkar \& Joshi 1983; Gadagkar et al. 1982). This species has an egg-to-adult developmental period of about 62 days (40-105 days, mean \pm s.d. $=$ $61.54 \pm 13.53$, sample size $=91$ individuals followed from egg-to-adult stage; R. Gadagkar, S. Bhagavan and S. Chandran, unpublished observations). I use survivorship data on workers to estimate $s$, the probability of survival of solitary foundresses for a period of 62 days.

Survivorship data for $R$. marginata workers were obtained by censusing marked females daily on two naturally occurring nests and then fitting a hazard function to the data according to Hjorth (1980) (see figure 2). Using the survivorship curve in figure 2, I compute the proportion of females having a lifespan of $i$ days as the difference between the probability of survival to the $i$ th day and that up to $i+1$ days. Equation (4) thus yields a value of 0.4335 for $\sigma^{*}$ whereas $s$, the probability of survival up to 62 days, obtained directly from figure 2 (or the appropriate 


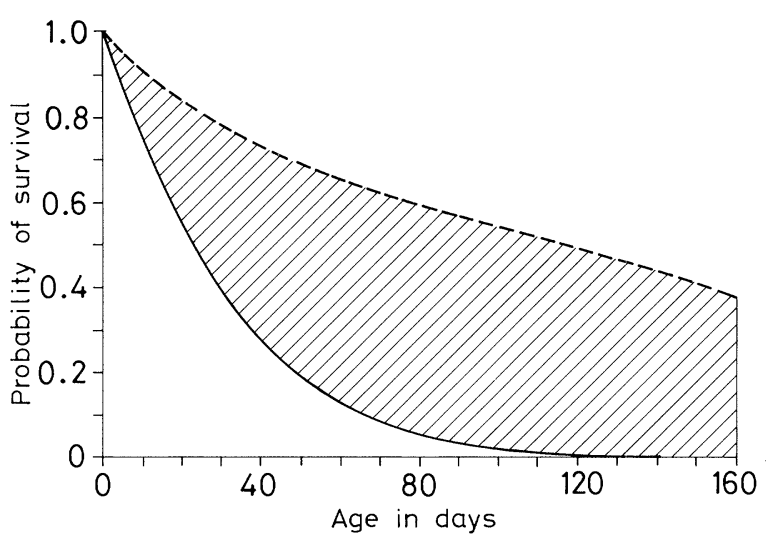

Figure 2. Survivorship curves for $R$. marginata females under field (solid line) and laboratory (broken line) conditions. The field survivorship curve was obtained by fitting the hazard function given by Hjorth (1980) to census data so that $l_{t}=$ $\left[\exp \left(-\delta t^{2} / 2\right)\right] /(1+\beta t)^{0 / \beta}$ where $l_{t}$ is the probability of surviving to the age $t$ and $\beta, \theta$ and $\delta$ are constants with values of $1.0 \times 10^{-5}, 2.8281 \times 10^{-2}$ and $1.8480 \times 10^{-4}$, respectively. The laboratory survivorship curve was obtained by fitting a quadratic model given by Bain (1978) to census data so that $l_{t}=\exp \left[-\left(a t+b t^{2} / 2+c t^{3} / 3\right)\right]$ where $a, b$ and $c$ are constants with values of $9.8973 \times 10^{-3},-1.2204 \times 10^{-4}$ and $6.984 \times 10^{-7}$, respectively.

Table 1. The advantage of assured fitness returns in the primitively eusocial wasp Ropalidia marginata

(See text for definitions of all parameters listed in the table. The results are very similar if original survivorship data are used rather than fitted functions in equations given in legends to figure 2.)

\begin{tabular}{lll}
\hline & $\begin{array}{l}\text { survivorship } \\
\text { data from } \\
\text { natural } \\
\text { colonies }\end{array}$ & $\begin{array}{l}\text { survivorship } \\
\text { data from } \\
\text { laboratory } \\
\text { colonies }\end{array}$ \\
\hline$s$ & 0.1215 & 0.6475 \\
$\sigma^{*}$ & 0.4335 & 0.7880 \\
threshold $r^{*}\left(\right.$ if $\left.b=\beta^{*}\right)$ & 0.1401 & 0.4108 \\
threshold $b / \beta^{*}\left(\right.$ if $\left.r^{*}=0.5\right)$ & 3.5679 & 1.2170 \\
relative strength compared & 2.3786 & 0.8113 \\
$\quad$ with haplodiploidy & & \\
{$\left[\left(\right.\right.$ threshold $\left.\left.b / \beta^{*}\right) / 1.5\right]$} & & \\
\hline
\end{tabular}

equation in the legend to figure 2) is 0.1215 (see table 1). This is the asymmetry between a worker who has the advantage of assured fitness returns and a solitary foundress who does not. Assuming that $b=\beta^{*}$, the threshold $r^{*}$ value required for the maintenance of eusociality is given by the equation:

threshold $r^{*}=s / 2 \sigma^{*}=0.1401$.

Alternatively, assuming that $r^{*}=r=0.5$, the threshold $b / \beta^{*}$ value required for the evolution of eusociality is given by the equation:

threshold $b / \beta^{*}=\sigma^{*} / s=3.5679$.

This means that, owing to the advantage of assured fitness returns, workers would break even with solitary foundresses in spite of rearing brood related to them by a mere 0.1401 or in spite of solitary foundresses being capable of performing 3.6 times more work per unit time. Compared with the maximum threshold $b / \beta^{*}$ value of 1.5 obtained under haplodiploidy (when the brood consists entirely of full-sisters), the assured fitness returns model is thus 2.4 times more effective than haplodiploidy in driving the evolution of eusociality (see table 1).

\section{SURVIVORSHIP DATA FROM LABORATORY EXPERIMENTS}

Probabilities of survival estimated from natural colonies almost certainly overestimate mortality rates. This is because disappearance from the colony is taken as death but some wasps leave their natal nests to initiate or join other nests. This is particularly true in the tropics where new nests are initiated throughout the year by wasps (sometimes of different ages) leaving their natal nests (Gadagkar et al. 1982; Gadagkar 1990). It is therefore necessary to correct for this bias in the estimated probabilities of survival. Besides, it is desirable to have some estimate of the range of values that the parameters in the model such as $s, \sigma^{*}$, threshold $r^{*}$ and threshold $b / \beta^{*}$ may take. In an attempt to satisfy these requirements, I repeat the foregoing analysis by using survivorship data from an experiment in which freshly eclosed females were maintained in isolation in the laboratory. Under these conditions mortality is underestimated because of the absence of predation and other risks of foraging in nature. To a first approximation, I liken values obtained from natural colonies and those obtained from the laboratory experiment to the lower and upper limits respectively, of the range of survival probabilities for this species. The survivorship curve under laboratory conditions (see figure 2) yields values of $s=$ $0.06475, \sigma^{*}=0.7880$, threshold $r^{*}=0.4108$ and threshold $b / \beta^{*}=1.2170$ (see table 1 ). These values are sufficient to satisfy inequality (3) although the potential advantage of assured fitness returns here is marginally less than the maximum advantage of haplodiploidy, the relative 'strength' of the former being 0.8 (see table 1).

\section{OTHER POLISTINE WASPS}

I now apply the assured fitness returns model to the four polistine wasp species that Queller (1989) has used to illustrate his head-start hypothesis. Equation (4) cannot be directly used to compute $\sigma^{*}$ because I do not know the shape of the survivorship curve for these species; nor do I have the original survivorship data. The probabilities of survival till the end of the brood developmental period $(s)$ for these species are, however, given by Queller (1989). Making the simplifying assumption of constant age-specific mortality, I therefore estimate the day-to-day probability of survival $m$ from the equation

$m^{n}=s$,

where $m$ is the probability of survival for one day, $n$ is the brood developmental period and $s$ is the probability of survival to $n$ days. I then compute the proportion of individuals surviving to $i$ days as $m^{i}$. The proportion of 
Table 2. Comparison of head-start hypothesis and the assured fitness returns model for Polistine wasps

\begin{tabular}{|c|c|c|c|c|c|c|}
\hline \multirow[b]{2}{*}{ species } & \multirow[b]{2}{*}{$\begin{array}{l}\text { Polistes } \\
\text { exclamans }^{\mathrm{a}}\end{array}$} & \multirow[b]{2}{*}{$\begin{array}{l}\text { Polistes } \\
\text { chinensis }^{\mathrm{a}}\end{array}$} & \multirow[b]{2}{*}{$\begin{array}{l}\text { Polistes } \\
\text { gallicus }^{\mathrm{a}}\end{array}$} & \multirow[b]{2}{*}{$\begin{array}{l}\text { Mischocyttarus } \\
\text { drewsen } i^{\mathrm{a}}\end{array}$} & \multicolumn{2}{|c|}{ Ropalidia marginata } \\
\hline & & & & & $\begin{array}{l}\text { survivors } \\
\text { natural } \\
\text { colonies }\end{array}$ & $\begin{array}{l}\text { data from } \\
\text { laboratory } \\
\text { colonies }\end{array}$ \\
\hline brood developmental period (days) ${ }^{\mathrm{b}}$ & 38 & 52 & 38 & 46 & 62 & 62 \\
\hline$s$ & 0.057 & 0.187 & 0.097 & 0.167 & 0.1215 & 0.6475 \\
\hline $\begin{array}{l}\text { threshold, } r^{*} \\
\text { threshold, } b / b^{*} \\
\text { relative strength }\end{array}$ & $\begin{array}{l}0.03 \\
17.4 \\
11.6\end{array}$ & $\begin{array}{l}\text { ead-start h } \\
0.09 \\
5.3 \\
3.5\end{array}$ & $\begin{array}{c}\text { othesis }^{\mathrm{e}} \\
0.05 \\
10.3 \\
6.9\end{array}$ & $\begin{array}{l}0.08 \\
6.0 \\
4.0\end{array}$ & - & $\begin{array}{l}- \\
- \\
-\end{array}$ \\
\hline \multicolumn{7}{|c|}{ assured fitness returns model (assuming constant age-specific mortality) } \\
\hline$m$ & 0.9274 & 0.9683 & 0.9404 & 0.9619 & 0.9666 & 0.9930 \\
\hline$\sigma^{*}$ & 0.3170 & 0.4774 & 0.3750 & 0.4569 & 0.4100 & 0.8078 \\
\hline threshold, $r^{*}$ & 0.0899 & 0.1958 & 0.1293 & 0.1828 & 0.1482 & 0.4008 \\
\hline threshold, $b / \beta^{*}$ & 5.5614 & 2.5529 & 3.8660 & 2.7359 & 3.3745 & 1.2476 \\
\hline relative strength ${ }^{d}$ & 3.7076 & 1.7019 & 2.5773 & 1.8239 & 2.2497 & 0.8317 \\
\hline
\end{tabular}

\footnotetext{
a Brood developmental period and $s$ values taken from Queller (1989).

"Values rounded off to the nearest day.

"Values in this part of the table are taken from Queller for comparison and the corresponding computations are not made for R. marginata.

"Compared with the advantage of haplodiploidy. See text for all parameters listed in the table.
}

individuals expected to have a lifespan of $i$ days being the difference between the proportion of individuals surviving to $i$ days and that to $i+1$ days, $\sigma^{*}$ may now be computed using equation (4). The results of this exercise (see table 2) show that the assured fitness returns model, as expected, gives a smaller advantage for eusociality compared with the presumed advantage of the head-start hypothesis. Nevertheless, these values are sufficient to satisfy inequality (3) and thus drive the evolution of eusociality.

To ascertain that the results of this analysis are not sensitive to my assumption of constant age-specific mortality, I repeat the analysis for data on $R$. marginata without using the entire survivorship data. Instead, I use the probability of survival until the end of the brood developmental period to compute the day-today probability of survival $(m)$ from equation (7), as I did for the other polistine wasps. Assuming constant age-specific mortality, I now estimate the proportions of individuals having a lifespan of $i$ days and then use equation (4) to compute $\sigma^{*}$. These results (table 2) are remarkably similar to those obtained with the explicit use of the survivorship function (see table 1). To the extent that survivorship curves of the polistine wasps used by Queller (1989) are qualitatively similar to those of $R$. marginala, this suggests that my results are different from those of Queller (1989) because of the differences between the head-start hypothesis and the assured fitness returns hypothesis rather than because of my assumption of constant age-specific mortality.

\section{THE $m . n$. PLOT}

Two crucial parameters in the assured fitness returns model are the day-to-day probability of survival $(\mathrm{m})$ and the brood developmental period $(n)$. The advantage of assured fitness returns would of course be most pronounced when the day-to-day probability of survival $(m)$ is low and the brood developmental period $(n)$ is high but both of these are likely to vary from species to species thus varying the efficacy of assured fitness returns in selecting for worker behaviour. I therefore plot the day-to-day probability of survival $(m)$ versus the brood developmental period $(n)$ (see figure 3). Assuming $r=r^{*}, b=\beta^{*}$ and a constant agespecific mortality, I delineate the regions in the $m \cdot n$

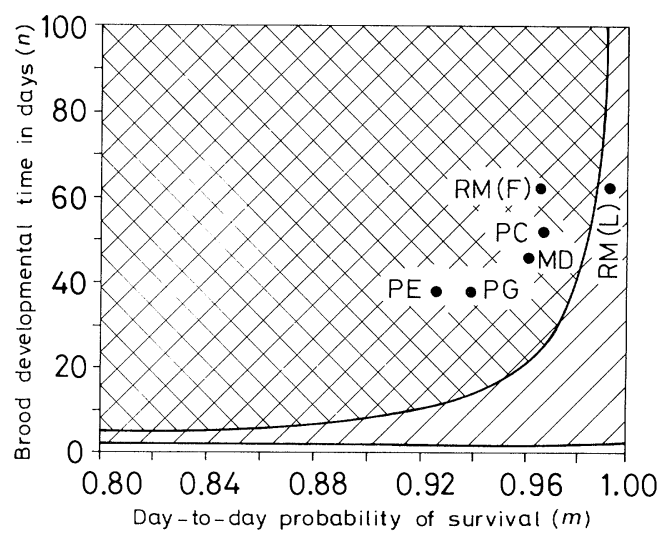

Figure 3. The $m \cdot n$ plot. Contour lines are shown in the parameter space of day-to-day probability of survival $(m)$ and the brood developmental period $(n)$ that separate the regions: (i) where there is no advantage of assured fitness returns $\left(b / \beta^{*}<1.0\right)$ (the narrow band of unhatched region close to the $x$-axis where $n<2$ ); (ii) where the advantage of assured fitness returns promotes worker behaviour but is less effective in doing so than haplodiploidy $\left(1.5>b / \beta^{*}>1.0\right)$ (hatched region) and (iii) the region where the advantage of assured fitness returns not only promotes worker bchaviour but is more effective in doing so than haplodiploidy $\left(b / \beta^{*}>\right.$ 1.5) (cross hatched region). The positions of all wasp species discussed in the text are also shown. $\mathrm{PE}=$ Polistes exclamans, $\mathrm{PG}=$ Polistes gallicus, $\mathrm{MD}=$ Mischocyttarus drewseni, $\mathrm{PC}=$ Polistes chinensis, RM $(\mathrm{F})=$ Ropalidia marginata (Survivorship data from natural colonies) and RM $(\mathrm{L})=$ Ropalidia marginata. (Survivorship data from a laboratory experiment.) 
parameter space where: (i) the assured fitness returns model does not promote the evolution of worker behaviour $\left(b / \beta^{*}<1.0\right)$; (ii) the assured fitness returns model promotes worker behaviour but is less effective at doing so than is haplodiploidy $\left(1.5>b / \beta^{*}>1.0\right)$; and (iii) it is more effective in selecting for workers behaviour than is haplodiploidy $\left(b / \beta^{*}>1.5\right)$. I then illustrate the use of the $m \cdot n$ plot by showing the positions of all wasp species considered in this paper. Plotting the positions of insects and other animals at different levels of sociality in the $m \cdot n$ space is bound to be instructive in delineating the factors that favour the evolution of eusociality. Relaxing any of the assumptions such as $r=r^{*}, b=\beta^{*}$ or that of constant agespecific mortality and replacing them with more realistic assumptions would of course be a simple matter as it would only involve changing the appropriate values in equations (4), (5) and (6).

\section{DISGUSSION}

Worker behaviour, and hence eusociality may thus be selected because of a special kind of asymmetry between the fitness of workers and that of solitary foundresses. But this asymmetry does not arise by the head start postulated by Queller (1989) by assuming that $s^{*}$ is inequality $(2)=1$ or by defining $b$ and $b^{*}$ in inequality (2) differently. Instead it arises because $\sigma^{*}$ in inequality (3), although less than 1 , will be greater than $s$ because, workers can get small values of fitness by contributing to the rearing of brood for short periods of time. Because threshold $r^{*}$ values for the evolution of eusociality lie between 0.4 (table 1) and 0.08 (table 2), the advantage of assured fitness returns will favour the evolution of worker behaviour. The assured fitness returns model thus provides a selective pressure for the evolution of worker behaviour even in the absence of haplodiploidy (Hamilton 1964a,b 1972), kin recognition (Gadagkar $1985 b$ ) or an ability on the part of workers to manipulate sex ratios (Trivers $\&$ Hare 1976). That threshold $r^{*}$ values lie between 0.4 and 0.08 also suggests that the advantage of assured fitness returns is likely to be 'resistant' to some reduction in worker-brood genetic relatedness caused by polygyny or polyandry.

I emphasize that to illustrate the advantage of assured fitness returns I have considered the simplest possible model. $b$ and $\beta^{*}$ are defined in identical fashion so that when $b=\beta^{*}$, solitary foundresses and workers are assumed to be able to do the same quantity of work per unit time. Similarly, $s$ and $\sigma^{*}$ are computed from the same survivorship functions so that solitary foundresses and workers are assumed to have the same mortality rates. In general, I assume no differences between solitary foundresses and workers except that workers are in a group and thus have assured fitness returns while solitary foundresses are alone and therefore do not have such an advantage. These assumptions may or may not hold under natural conditions. For instance, $\beta^{*}$ may be greater than $b$ because workers may be capable of doing more work per unit time than solitary foundresses on account of the advantages of division of labour. Alternatively, workers may have lower mortality rates compared with solitary foundresses because of other advantages of group life. However, any such deviations from my simplified assumptions can be readily incorporated into the model.

The model assumes that the colony cycle ends with the production of one batch of brood. For most polistine wasps, there are at least two successive batches of broods. Besides, the first batch of brood generally consists of workers whereas reproductives are produced in the second batch of brood. This feature of natural colonies too can be incorporated into the model. Yet another simplified feature of the model is that $s$ and $\sigma^{*}$ are computed by considering the actual egg to adult brood developmental period in days. This may be reasonable for a life cycle of the kind exhibited by polistine wasps where larvae are progressively provisioned and even the pupae require the presence of the adults to protect them from predators. But it may be quite inappropriate for other kinds of situations such as those species where there is mass provisioning (Wilson 1971, p. 21). This difficulty also can be easily overcome by computing $s$ and $\sigma^{*}$ by using the actual number of days of work required on the part of the adults for brood development rather than the number of days that the brood take to become adults. The $m \cdot n$ plot in figure 3 may thus be applied to a variety of animal species (perhaps including birds and mammals), provided $n$ (the brood developmental period) is defined as the period of dependence of the offspring on the adults.

It must also be mentioned that the assured fitness returns I have postulated for workers is only 'assured' relative to the uncertainty in fitness returns for solitary foundresses who lose everything if they die before their brood complete development. There must be a small uncertainty even for the workers because their nests may also fail or be abandoned before the completion of brood development. Although the chances of this happening are quite small, thereby making the asymmetry between workers and solitary foundresses in this regard worth considering as a potential factor in favour of eusociality, this suggests that the advantage of assured fitness returns will not be the same for all workers. There would be greater uncertainty of fitness returns for workers who care for very young larvae and thus fitness returns will get increasingly assured as the brood gets older. When brood are produced asynchronously so that any nest contains offspring of different developmental stages, this may not matter but, to the extent that brood are synchronously produced, selection for worker behaviour will depend on the kind of nest that is available to a worker. If the probability that a multiple foundress nest fails before producing adult offspring is known, the model can be suitably modified to incorporate such mild uncertainty as may exist in the fitness returns for workers.

Queller's (1989) head-start hypothesis, even if correct, only applies to individuals who have an opportunity to choose between (i) staying back on their natal nest and assisting their mother (and thus having access to young of various ages, at least some of which can be quickly brought to the age of in- 
dependence) or (ii) leaving to start their own solitary foundress nest. The assured fitness returns model is more general and in addition to applying to this scenario is also applicable to individuals who have a choice between (i) becoming solitary foundresses or (ii) joining a multiple foundress association as a subordinate co-foundress. Here the subordinate co-foundresses who take on the role of workers do not have immediate access to young of various ages but they do have the advantage of assured fitness returns. One consequence of this is that the assured fitness returns model is as applicable to the quasisocial or semisocial route for the evolution of eusociality as it is to the subsocial route (Wilson 1971, p. 99).

The assured fitness returns model thus leads to a third possible kind of pre-disposition towards eusociality. I suggest that this be called 'life historical predisposition'. The idea of life historical pre-disposition permits us to focus on certain novel factors that could promote eusociality. It is already clear from figure 3 that a combination of high adult mortality rates and long brood developmental (or dependence) times would lead to life historical pre-disposition of a species towards eusociality. But, even if the mortality rates and brood developmental times per se are not unusual, the same consequence will be obtained if there is need for a long and elaborate preparation for reproduction. This could be due to delayed attainment of reproductive maturity or due to the need to build nests or dig tunnels; all of these would serve to increase the probability of the lone foundress dying before her brood are brought to the age of independence. Consequently, the advantage of assured fitness returns to individuals that live in groups can tilt the scale in favour of worker behaviour.

I thank Joan Strassmann for letting me see the paper by Queller (1989) in unpublished manuscript form, U. A. Lavaraj, P. K. Vaidya and A. P. Gore for fitting the survivorship functions, and R. H. Grozier, M. Gadgil, W. D. Hamilton, N. V. Joshi, C. D. Michener, V. Nanjundiah, P. Nonacs, D. G. Queller, W. T. Wcislo, E. O. Wilson and four anonymous reviewers for helpful comments on previous versions of this paper. Supported in part by a grant from the Indian National Science Academy, New Delhi.

\section{REFERENGES}

Alexander, R. D. 1974 The evolution of social behavior. A. Rev. Ecol. Syst. 5, 325-383.

Bain, Lee J. 1978 Statistical analysis of reliability and life-testing models. Theory and methods. New York: Marcel Dekker.

Craig, R. 1979 Parental manipulation, kin selection, and the evolution of altruism. Evolution 33, 319-334.

Darwin, C. 1859 The origin of species. New York: Collier Books (1962).

Gadagkar, R. 1980 Dominance hierarchy and division of labour in the social wasp, Ropalidia marginata (Lep.) (Hymenoptera: Vespidae). Curr. Sci. 49, 772-775.

Gadagkar, R. 1985 a Evolution of insect sociality - a review of some attempts to test modern theories. Proc. Indian Acad. Sci. (Anim. Sci.) 94, 309-324.

Gadagkar, R. $1985 b$ Kin recognition in social insects and other animals - a review of recent findings and a con- sideration of their relevance for the theory of kin selection. Proc. Indian Acad. Sci. (Anim. Sci.) 94, 587-621.

Gadagkar, R. 1990 a Belonogaster, Mischocyttarus, Parapolybia, and independent-founding Ropalidia. In The social biology of wasps, (ed. K. G. Ross \& R. W. Matthews) Ithaca, New York: Cornell University Press. (In the press.)

Gadagkar, R. $1990 b$ The haplodiploidy threshold and social evolution. Curr. Sci. (In the press.)

Gadagkar, R. \& Joshi, N. V. 1983 Quantitative ethology of social wasps: time-activity budgets and caste differentiation in Ropalidia marginata (Lep.) (Hymenoptera: Vespidae). Anim. Behav. 31, 26-31.

Gadagkar, R., Gadgil, M., Joshi, N. V. \& Mahabal, A. S. 1982 Observations on the natural history and population ecology of the social wasp Ropalidia marginata (Lep.) from peninsular India. (Hymenoptera: Vespidae). Proc. Indian Acad. Sci. (Anim. Sci.) 91, 539-552.

Gadagkar, R., Vinutha, C., Shanubhogue, A. \& Gore, A. P. 1988 Pre-imaginal biasing of caste in a primitively eusocial insect. Proc. R. Soc. Lond. B 223, 175-189.

Gadagkar, R., Bhagavan, S., Malpe, R. \& Vinutha, C. 1990 On reconfirming the evidence for pre-imaginal caste bias in a primitively eusocial wasp. Proc. Indian Acad. Sci. (Anim. Sci.) 99, 141-150.

Gamboa, G. J. 1978 Intraspecific Defense: advantage of social cooperation among paper wasp foundresses. Science, Wash. 199, 1463-1465.

Gibo, D. L. 1978 The selective advantage of foundress associations in Polistes fuscatus (Hymenoptera: Vespidae): a field study of the effects of predation on productivity. Can. Ent. 110, 519-540.

Hamilton, W. D. $1964 a$ The genetical evolution of social behaviour. I. J. theor. Biol. 7, 1-16.

Hamilton, W. D. $1964 b$ The genetical evolution of social behaviour. II. J. theor. Biol. 7, 17-52.

Hamilton, W. D. 1972 Altruism and related phenomena, mainly in social insects. A. Rev. Ecol. Syst. 3, 192-232.

Hjorth 1980 A reliability distribution with increasing, decreasing, constant and bath-tub shaped failure rates. Technometrics 22, 99-107.

Jarvis, J. U. M. 1981 Eusociality in a mammal : cooperative breeding in naked mole-rat colonies. Science, Wash. 212, $571-573$.

Lin, N. \& Michener, C. D. 1972 Evolution of sociality in insects. Q. Rev. Biol. 47, 131-159.

Michener, C. D. 1969 Comparative social behavior of bees. A. Rev. Ent. 14, 299-342.

Muralidharan, K., Shaila, M. S. \& Gadagkar, R. 1986 Evidence for multiple mating in the primitively eusocial wasp Ropalidia marginata (Lep.) (Hymenoptera: Vespidae). J. Genet. 65, 153-158.

Page, R. E. Jr \& Metcalf, R. A. 1982 Multiple mating, sperm utilization and social evolution. Am. Nat. 119, 263-281.

Page, R. E. Jr 1986 Sperm utilization in social insects. $A$. Rev. Ent. 31, 297-320.

Queller, D. C. 1989 The evolution of eusociality: reproductive head starts of workers. Proc. natn. Acad. Sci. U.S.A. 86, 3224-3226.

Queller, D. C., Strassmann, J. E. \& Hughes, C. R. 1988 Genetic relatedness in colonies of tropical wasps with multiple queens. Science, Wash. 242, 1155-1157.

Ross, K. G. 1986 Kin selection and the problem of sperm utilization in social insects Nature, Lond. 323, 798-800.

Starr, C. K. 1984 Sperm competition, kinship, and sociality in the aculeate Hymenoptera. In Sperm competition and the evolution of animal mating systems (ed. R. L. Smith), pp. 427-464. New York: Academic Press. 
Strassmann, J. E., Queller, D. C. \& Hughes, C. R. 1988 Predation and the evolution of sociality in the paper wasp Polistes bellicosus. Ecology 69, 1497-1505.

Trivers, R. L. \& Hare, H. 1976 Haplodiploidy and the evolution of social insects. Science, Wash. 191, 249-263.

Venkataraman, A. B., Swarnalatha, V. B., Nair, P. \& Gadagkar, R. 1988 The mechanism of nestmate discrimination in the tropical social wasp Ropalidia marginata and its implications for the evolution of sociality. Behav. Ecol. Sociobiol. 23, 271-279.
West-Eberhard, M.J. 1978 Polygyny and the evolution of social behavior in wasps. J. Kans. Ent. Soc. 51, 832-856.

West-Eberhard, M.J. 1975 The evolution of social behavior by kin selection. Q. Rev. Biol. 50, 1-33.

Wilson, E. O. 1971 The insect societies. Cambridge, Massachusetts: Harvard University Press.

(Submitted by W. D. Hamilton; Received 9 March 1990; Accepted 6 April 1990) 